[DOI: 10.24214/jecet.A.10.1.01524.]

Juurnal of Enviranmental Science, Computer Science and Engineering \& Technology

An International Peer Review E-3 Journal of Sciences and Technology

Available online at www.jecet.org

Section A: Environmental Science

Research Article

\title{
Experimental investigation into effect of perforated caisson in wave reflection of Breakwater (case study of Tombak port)
}

\author{
Amin kariman $^{1 *}$, Omid Rasouli Disfani' ${ }^{1}$ Amir Alikhani \\ 1* Master of Science, Department of Civil Engineering, College of Engineering, University of Qom, \\ ${ }^{2}$ Professor Assistant, Department of Civil Engineering, College of Engineering, University of Qom
}

Received: 04 January 2020; Revised: 15 January 2020; Accepted: 27 January 2020

\begin{abstract}
In this paper, we investigated the wave reflected from the perforated breakwater caisson. The study is for physical models and laboratory. Wave reflection from the breakwater can cause many problems for vessels so to reduce wave reflection from breakwater, perforated caisson can be used. This is a test case that wave reflection when a perforated wall is in front of the main wall and two perforated wall is in front of the main wall is to be measured and the impact of the perforated walls on wave reflection checked. The perforated walls are slot and the porosity is $1 / 2$ and $1 / 3$. Tombak port was used for modeling and the size of breakwater and the waves information related to Tombak port breakwater. The experiments conducted in wave flume of the Soil Conservation and Watershed Management Research Center
\end{abstract}

Keywords: caisson perforated, physical modeling, Tombak Port, reflection, breakwater.

\section{INTRODUCTION}

In Iran, as one of the developing countries with long maritime borders and population growth in coastal areas, construction of wharves according to fundamental role in the development of the country and 
consequently the construction of breakwaters to protect coasts and ports is important ${ }^{[1]}$. Using the caisson for construction of port and breakwater in areas of the sea that has a great depth and has a saving cost and export Tombak port in Bushehr province that including deep-water in this region is privileged for construction of wharves ${ }^{[2,3]}$.

\section{MATERIALS AND METHODS}

The necessity of research: Modeling as a design tool can simulate reality in a way that effect of desired phenomenon of the measure and field observations on the performance of a hypothetical structures and their environment is predictable. Representation hydraulic phenomena are made physically (by physical models and scale) or mathematically (analytical and numerical models). Examples of hydraulic phenomena and processes related to marine structures, that is possible for model, are: Water level, current, wave reflection, wave run up, wave overtopping, wave passes, Scour, associated forces and structural stability of certain parts.

The advantages of physical models are the modeling of real phenomena with all their details. If the physical model with sufficient accuracy is made and similarity rules are observed, the results can be used not only in design of associated structures but also to investigate mathematical and numerical physical phenomena will be applied.In fact, physical model models real terms by applying simplified. The cost of construction of marine structures high enough that constructing of physical model becomes economically justified.

\section{RESULTS AND DISCUSSION}

The establishment of model:This phase is the most important step in the research. If at this stage we do not have enough accuracy, we will see many errors in the experiments, and it is noteworthy that experiments are never ideal and in the best there will be little margin of error. The experiments at the Research Center of Ministry of Agriculture, Soil Conservation and Watershed Management are done. In this part, the test equipment and the establishment of model and data obtained from the tests will be presented. At first the laboratory equipment is investigated.

Wave flume: Flume of Soil and Water Conservation Research Center of Ministry of Agriculture has 33 meters long, 5.5 meters wide and 5.1 meters deep. In Figures 1 and 2 you'll see the plan and shape of the flume.

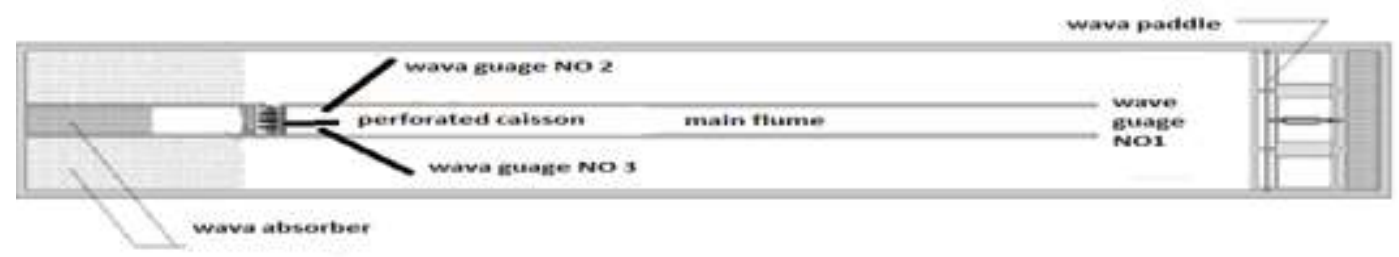

Figure1: wave flume plan

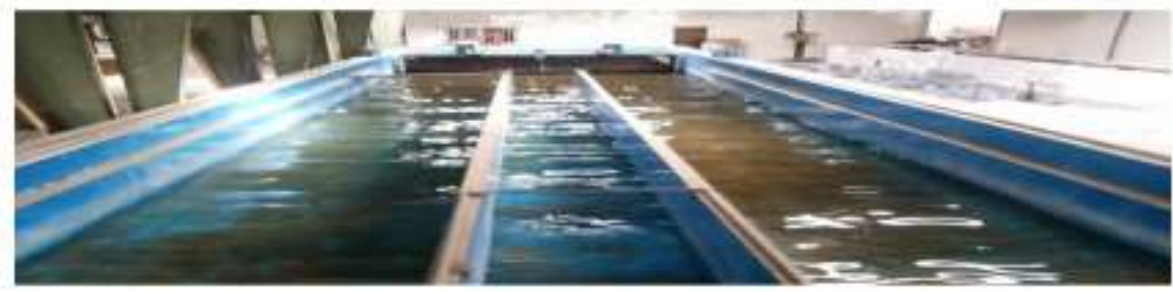

Figure 2: wave flume shape 
Experiments in the middle of the plan that less wide (1 meter) has been created which makes it less transverse waves.

Model data: In Figure 3, geographical location of Tombak port in Bushehr and Persian Gulf compared to adjacent ports is shown. Figure $\mathbf{4}$ and 5, respectively, shows three-dimensional structural model and caisson breakwater type section

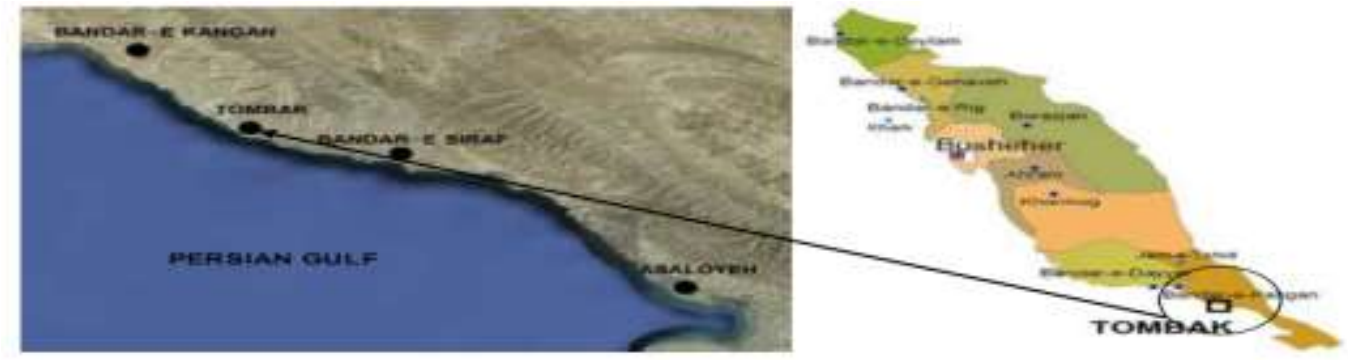

Figure 3: Tombak port position in the Persian Gulf

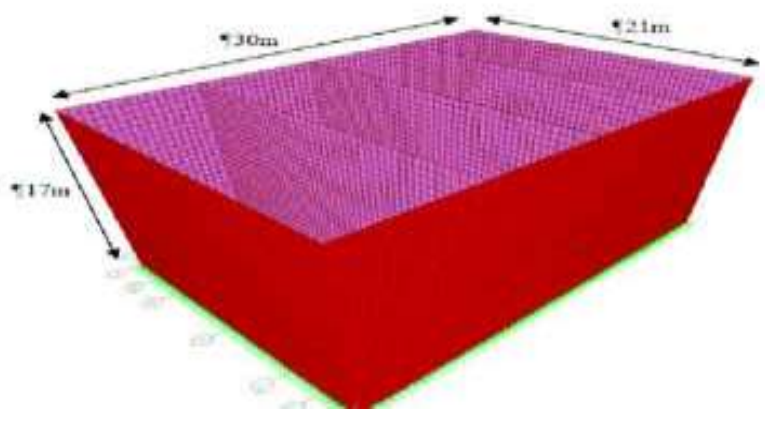

Figure 4: three-dimensional structural caisson model.

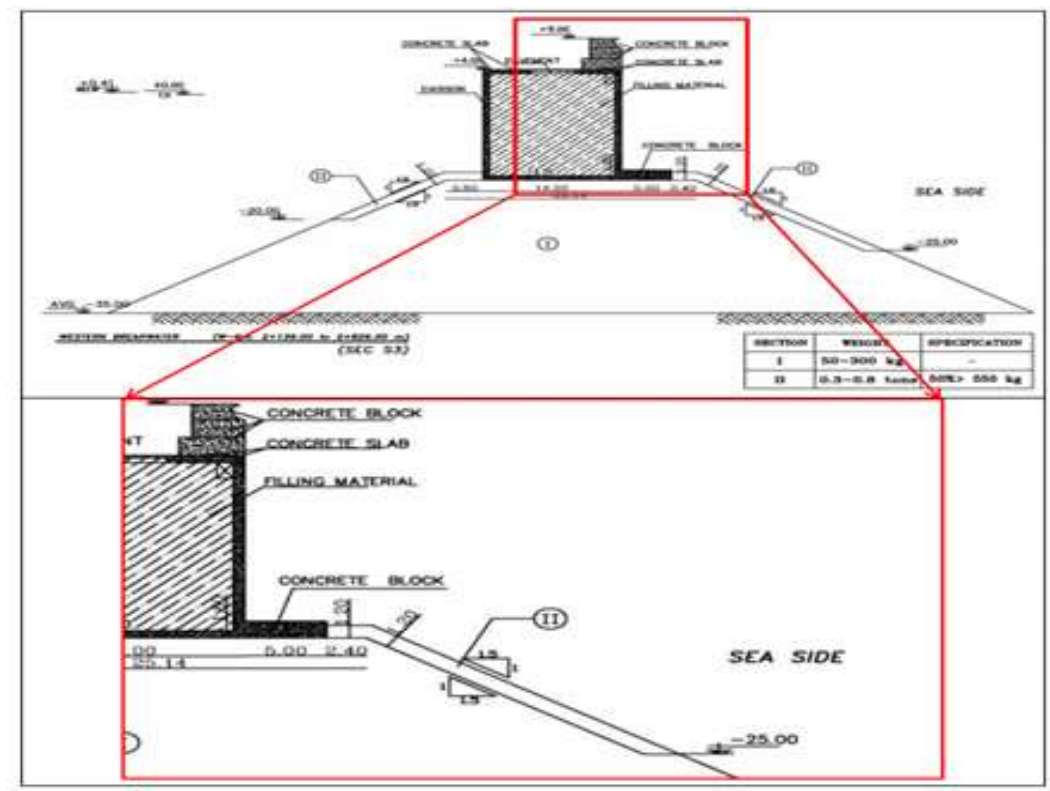

Figure 5: caisson breakwater type section. 
As you can see in Figure 4 and 5 sections and dimensions of caisson breakwater structure and foundation gravel that caisson put on it and also water depth shown is important for model design. Water levels caused by tides has been shown in tables $\mathbf{1}$ and $\mathbf{2}$. The different water heights in the modeling based on this information.

Table 1: Tides height in Tombak area

\begin{tabular}{|c|c|c|}
\hline Mean Higher High Water & MHHW & +1.88 m C.D. \\
\hline Mean Lower High Water & MLHW & +1.69 m C.D. \\
\hline Mean Sea Level & MSL & +1.23 m C.D. \\
\hline Mean Higher Low Water & MHLW & +0.90 m C.D. \\
\hline Mean Lower Low Water & MLLW & +0.41 m C.D. \\
\hline Lowest Astronomical Tide & LAT & $+0.00 \mathrm{~m}$ C.D. \\
\hline
\end{tabular}

Table 2: Raising the water level due to the wind

\begin{tabular}{|c|c|}
\hline Return Period (Year) & Wind setup \\
\hline 1 & 25 \\
\hline 5 & 31.4 \\
\hline 10 & 34.3 \\
\hline 25 & 38.4 \\
\hline 50 & 41.7 \\
\hline 100 & 45.2 \\
\hline
\end{tabular}

Table 3 contains information about wave height, period and return time, and wave direction compared to the break water section.

Table 3: Maximum design wave for different return periods and directions

\begin{tabular}{|c|c|c|c|c|c|c|c|}
\hline $\begin{array}{c}\text { Return } \\
\text { period }\end{array}$ & $\boldsymbol{H} \boldsymbol{s}_{\max }$ & $\boldsymbol{T}_{\boldsymbol{p}}$ & $\begin{array}{c}\text { Return } \\
\text { period }\end{array}$ & $\begin{array}{c}\text { Wave } \\
\text { impact } \\
\text { angle }\end{array}$ & $\boldsymbol{H} \boldsymbol{s}_{\boldsymbol{m a x}}$ & $\boldsymbol{T}_{\boldsymbol{p}}$ & $\begin{array}{c}\text { Wave } \\
\text { impact } \\
\text { angle }\end{array}$ \\
\hline 1 & 0.32 & 4.08 & 136.07 & 1 & 0.89 & 4.35 & 224.92 \\
\hline 10 & 0.43 & 4.70 & 136.03 & 10 & 1.21 & 4.91 & 224.99 \\
\hline 50 & 0.53 & 4.99 & 136.12 & 50 & $1 / 48$ & $5 / 31$ & $224 / 97$ \\
\hline 100 & 0.56 & 5.20 & 136.03 & 100 & $1 / 61$ & $5 / 62$ & $224 / 93$ \\
\hline 1 & 0.64 & 4.79 & 139.74 & 1 & $0 / 99$ & $4 / 65$ & $246 / 42$ \\
\hline 10 & 1.00 & 5.8 & 139.80 & 10 & $1 / 35$ & $5 / 23$ & $246 / 05$ \\
\hline 50 & 1.32 & 6.62 & 139.97 & 50 & $1 / 64$ & $5 / 61$ & $245 / 87$ \\
\hline 100 & 1.48 & 6.98 & 140.02 & 100 & $1 / 77$ & $5 / 79$ & $245 / 68$ \\
\hline 1 & 1.42 & $5 . / 81$ & 146.25 & 1 & $2 / 45$ & $7 / 26$ & $264 / 32$ \\
\hline 10 & 2.20 & 6.99 & 148.05 & 10 & $3 / 26$ & $8 / 20$ & $263 / 04$ \\
\hline 50 & 2.90 & 7.74 & 149.59 & 50 & $3 / 91$ & $8 / 61$ & $261 / 98$ \\
\hline
\end{tabular}




\begin{tabular}{|c|c|c|c|c|c|c|c|}
\hline 100 & 3.24 & 8.31 & 150.29 & 100 & $4 / 22$ & $9 / 06$ & $261 / 48$ \\
\hline 1 & 1.76 & 6.04 & 159.35 & 1 & $2 / 11$ & $6 / 96$ & $276 / 68$ \\
\hline 10 & 2.91 & 7.60 & 161.82 & 10 & $2 / 73$ & $7 / 69$ & $275 / 67$ \\
\hline 50 & 4.03 & 8.57 & 163.16 & 50 & $3 / 21$ & $8 / 34$ & $274 / 68$ \\
\hline 100 & 4.64 & 9.25 & 163.74 & 100 & $3 / 45$ & $8 / 46$ & $274 / 27$ \\
\hline 1 & 1.00 & 4.74 & 178.35 & 1 & $0 / 96$ & $5 / 25$ & $284 / 89$ \\
\hline 10 & 1.60 & 5.72 & 179.71 & 10 & $1 / 44$ & $6 / 27$ & $284 / 61$ \\
\hline 50 & 2.21 & 6.39 & 180.00 & 50 & $1 / 85$ & $6 / 92$ & $284 / 15$ \\
\hline 100 & 2.53 & 6.89 & 180.25 & 100 & $2 / 06$ & $7 / 07$ & $283 / 68$ \\
\hline 1 & 0.87 & 4.34 & 201.95 & 1 & $0 / 41$ & $4 / 29$ & $287 / 99$ \\
\hline 10 & 1.33 & 5.23 & 202.95 & 10 & $0 / 58$ & $4 / 77$ & $287 / 83$ \\
\hline 50 & 1.78 & 5.83 & 202.30 & 50 & $0 / 70$ & $5 / 17$ & $287 / 93$ \\
\hline 100 & 2.02 & 6.26 & 202.32 & 100 & $0 / 76$ & $5 / 25$ & $287 / 77$ \\
\hline
\end{tabular}

The process of experimental model construction: According to very large dimensions of the structures and wave flume can have a certain depth water, scale 1/80 was chosen for the model.

$$
N_{\mathrm{L}}=80
$$

The maximum and minimum water level in the design of the test is determined as follows:

DWL max: Maximum water level in design: MHHW $+0 / 34$ (for wind) $=1 / 88+0 / 34=2 / 22 \mathrm{~m}$

The seabed at a depth of $-35 \mathrm{~m}$, so water depth according to the scale $\left(\mathrm{N}_{\mathrm{L}}=80\right)$ in the flume is determined as follows:

$$
h_{1}: \frac{35+2.22}{80} \approx 47 \mathrm{~cm}
$$

The rubble mound height is equal to $22 \mathrm{~m}$ in main sample. So in the model it is equal to:

$22 / 80=27 / 5 \mathrm{~cm}$

The caisson height is equal to $22 \mathrm{~m}$ in main sample. So in the model it is equal to:

$22 / 80=27 / 5 \mathrm{~cm}$

So total height of the model is $55 \mathrm{~cm}$. other part is modeled by $\mathrm{N}_{\mathrm{L}}=80$

We use Table 3For wave height and period and we compare them according modeling relations.

We have been used $\mathrm{N}_{\mathrm{L}}$ for wave height modeling and NT $-\sqrt{N_{L}}$ for period modeling ...... so wave height and period is equal to: 
Table 4: Test height and period

\begin{tabular}{|c|c|c|c|}
\hline $\mathrm{H}(\mathrm{cm})$ & $\mathrm{T}(\mathrm{s})$ & $\mathrm{H}(\mathrm{cm})$ & $\mathrm{T}(\mathrm{s})$ \\
\hline $1 / 25$ & $0 / 65$ & $3 / 63$ & $0 / 87$ \\
\hline $1 / 65$ & $0 / 74$ & $4 / 08$ & $0 / 92$ \\
\hline $1 / 85$ & $0 / 78$ & $2 / 00$ & $0 / 64$ \\
\hline $1 / 80$ & $0 / 70$ & $3 / 64$ & $0 / 85$ \\
\hline $2 / 31$ & $0 / 77$ & $2 / 01$ & $0 / 63$ \\
\hline $2 / 58$ & $0 / 79$ & $5 / 28$ & $1 / 01$ \\
\hline $1 / 78$ & $0 / 65$ & $2 / 53$ & $0 / 70$ \\
\hline $2 / 64$ & $0 / 78$ & $2 / 05$ & $0 / 63$ \\
\hline $2 / 75$ & $0 / 78$ & $2 / 23$ & $0 / 65$ \\
\hline $4 / 01$ & $0 / 93$ & $4 / 89$ & $0 / 96$ \\
\hline $3 / 41$ & $0 / 86$ & $2 / 21$ & $0 / 65$ \\
\hline $3 / 06$ & $0 / 81$ & $3 / 16$ & $0 / 77$ \\
\hline $4 / 05$ & $0 / 93$ & $2 / 76$ & $0 / 71$ \\
\hline $4 / 31$ & $0 / 95$ & $5 / 80$ & $1 / 03$ \\
\hline $2 / 20$ & $0 / 68$ & $5 / 04$ & $0 / 96$ \\
\hline
\end{tabular}

In Table 4,and figure 6 and 7 periods which have less than 6.0 seconds are removed caused by the effect of transverse waves.

For caisson modeling, three plates were used as follows:

- $\quad$ Rigid plate (with dimension of $100 * 30$ )

- Porous plate (with dimension of $100 * 30$ ), so that it is rigid $10 \mathrm{~cm}$ and the gap between the rigid parts is $10 \mathrm{~cm}$, so its porosity is $1 / 2$.

- Porous plate (with dimension of $100 * 30$ ), so that it is rigid $14 \mathrm{~cm}$ and the gap between the rigid parts is $7 \mathrm{~cm}$, so its porosity is $1 / 3$.

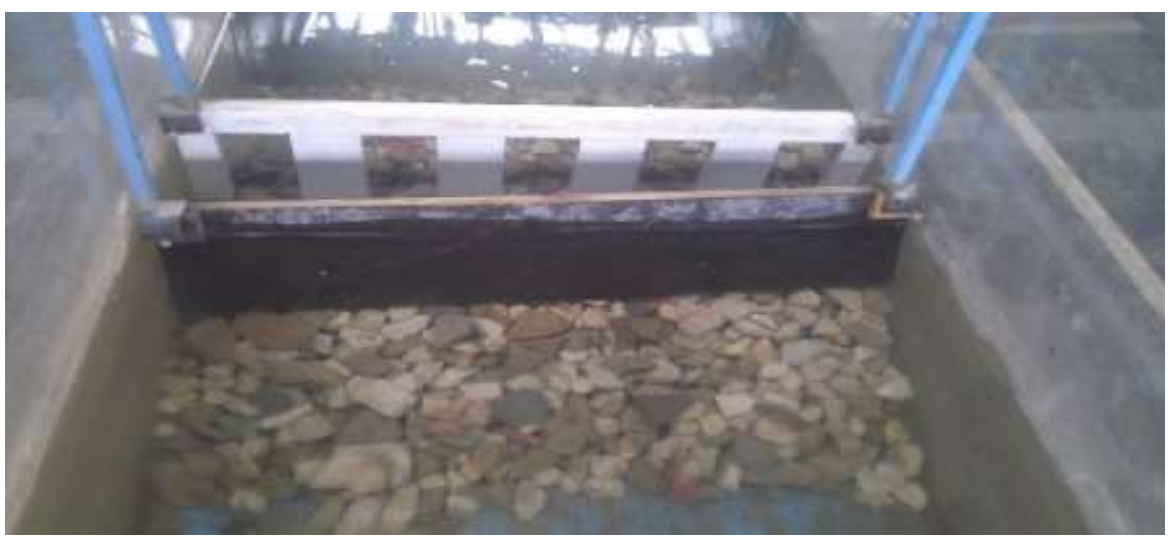

Figure 6: Caisson modeling with one porous plate 


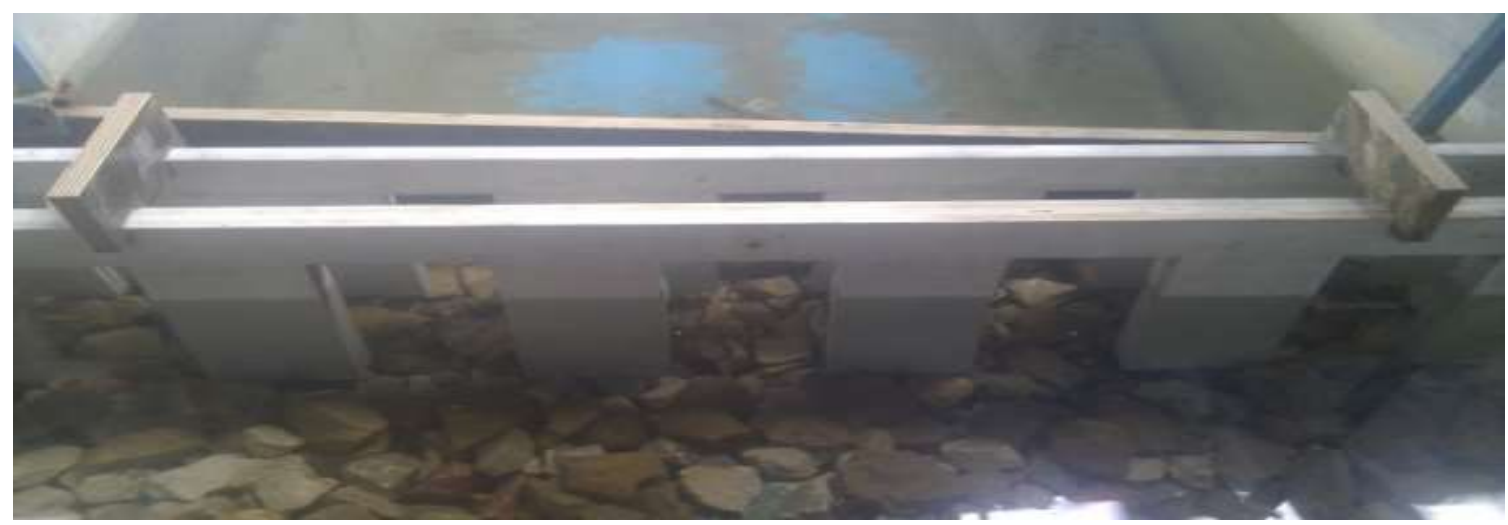

Figure 7: Caisson modeling with two porous plate

Experiment results for breakwater with one porous plate. In this part, we investigate breakwater with one porous plate experiment results Table 5, Figure 8.

Table 5: reflection factor results for depth $47 \mathrm{~cm}$ with one absorbing wave

\begin{tabular}{|c|c|c|c|c|c|c|}
\hline Number & T (s) & Hi (cm) & Hr $(\mathbf{c m})$ & $\mathbf{C r}$ & $\mathbf{L}$ & $\mathbf{K}$ \\
\hline $\mathbf{1}$ & $0 / 65$ & $2 / 50$ & $1 / 29$ & $0 / 52$ & $0 / 66$ & $0 / 038$ \\
\hline $\mathbf{2}$ & $0 / 78$ & $2 / 23$ & $1 / 15$ & $0 / 52$ & $0 / 95$ & $0 / 023$ \\
\hline $\mathbf{3}$ & $0 / 70$ & $2 / 97$ & $2 / 20$ & $0 / 74$ & $0 / 77$ & $0 / 039$ \\
\hline $\mathbf{4}$ & $0 / 77$ & $1 / 90$ & $0 / 79$ & $0 / 42$ & $0 / 94$ & $0 / 020$ \\
\hline $\mathbf{5}$ & $0 / 65$ & $2 / 40$ & $0 / 89$ & $0 / 37$ & $0 / 66$ & $0 / 036$ \\
\hline $\mathbf{6}$ & $0 / 78$ & $2 / 10$ & $1 / 37$ & $0 / 65$ & $0 / 95$ & $0 / 022$ \\
\hline $\mathbf{7}$ & $0 / 78$ & $2 / 62$ & $1 / 72$ & $0 / 66$ & $0 / 95$ & $0 / 027$ \\
\hline $\mathbf{8}$ & $0 / 93$ & $4 / 71$ & $2 / 90$ & $0 / 62$ & $1 / 36$ & $0 / 035$ \\
\hline $\mathbf{9}$ & $0 / 86$ & $4 / 11$ & $3 / 10$ & $0 / 75$ & $1 / 15$ & $0 / 036$ \\
\hline $\mathbf{1 0}$ & $0 / 81$ & $3 / 50$ & $2 / 38$ & $0 / 68$ & $1 / 03$ & $0 / 034$ \\
\hline $\mathbf{1 1}$ & $0 / 93$ & $4 / 83$ & $3 / 63$ & $0 / 75$ & $1 / 35$ & $0 / 036$ \\
\hline $\mathbf{1 2}$ & $0 / 95$ & $4 / 70$ & $2 / 52$ & $0 / 54$ & $1 / 40$ & $0 / 034$ \\
\hline $\mathbf{1 3}$ & $0 / 68$ & $2 / 50$ & $1 / 45$ & $0 / 58$ & $0 / 71$ & $0 / 035$ \\
\hline $\mathbf{1 4}$ & $0 / 87$ & $4 / 62$ & $3 / 40$ & $0 / 74$ & $1 / 17$ & $0 / 039$ \\
\hline $\mathbf{1 5}$ & $0 / 92$ & $5 / 55$ & $3 / 50$ & $0 / 63$ & $1 / 31$ & $0 / 042$ \\
\hline $\mathbf{1 6}$ & $0 / 64$ & $1 / 37$ & $0 / 91$ & $0 / 66$ & $0 / 64$ & $0 / 021$ \\
\hline $\mathbf{1 7}$ & $0 / 85$ & $4 / 97$ & $3 / 41$ & $0 / 69$ & $1 / 13$ & $0 / 044$ \\
\hline $\mathbf{1 8}$ & $1 / 01$ & $7 / 60$ & $5 / 08$ & $0 / 67$ & $1 / 60$ & $0 / 047$ \\
\hline $\mathbf{1 9}$ & $0 / 70$ & $4 / 56$ & $1 / 86$ & $0 / 41$ & $0 / 77$ & $0 / 060$ \\
\hline $\mathbf{2 0}$ & $0 / 63$ & $1 / 70$ & $1 / 05$ & $0 / 62$ & $0 / 61$ & $0 / 028$ \\
\hline $\mathbf{2 1}$ & $0 / 65$ & $2 / 29$ & $1 / 36$ & $0 / 59$ & $0 / 66$ & $0 / 035$ \\
\hline $\mathbf{2 2}$ & $0 / 96$ & $5 / 19$ & $3 / 05$ & $0 / 59$ & $1 / 45$ & $0 / 036$ \\
\hline $\mathbf{2 3}$ & $0 / 77$ & $2 / 29$ & $1 / 55$ & $0 / 68$ & $0 / 93$ & $0 / 025$ \\
\hline $\mathbf{2 4}$ & $0 / 71$ & $3 / 80$ & $2 / 10$ & $0 / 55$ & $0 / 80$ & $0 / 048$ \\
\hline $\mathbf{2 5}$ & $0 / 96$ & $7 / 17$ & $3 / 61$ & $0 / 50$ & $1 / 43$ & $0 / 050$ \\
\hline
\end{tabular}




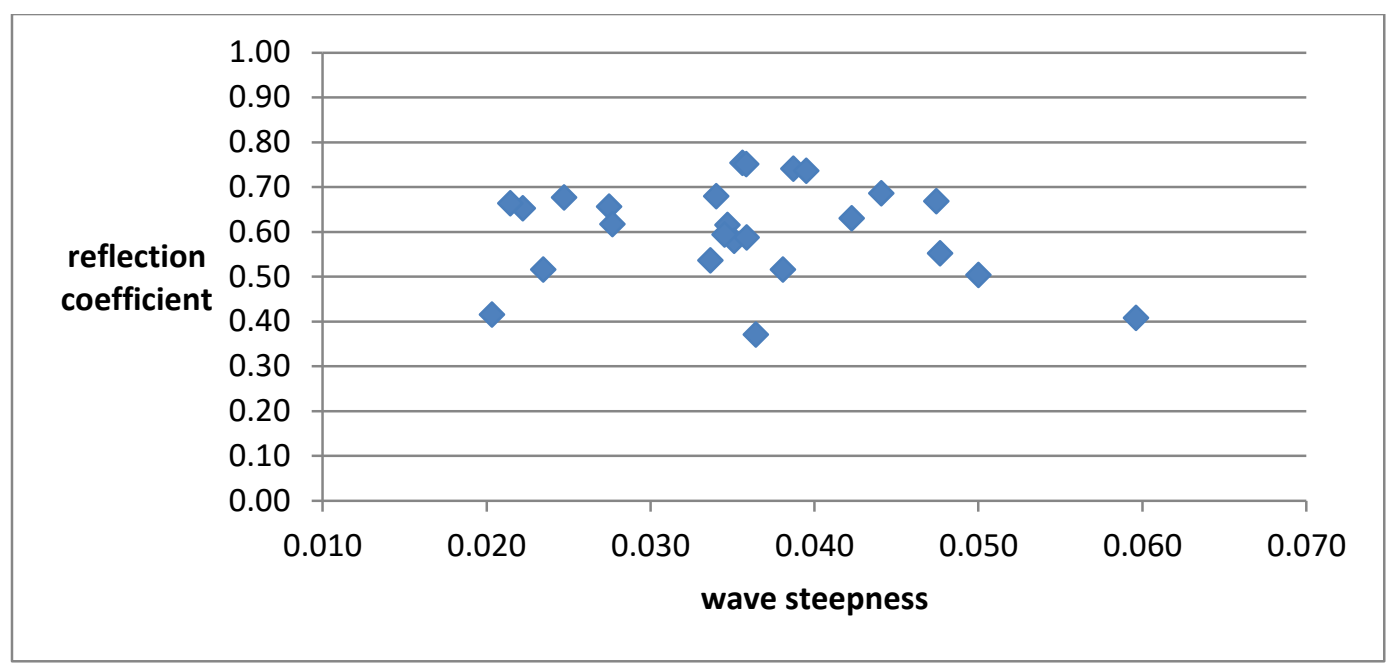

Figure 8: The dispersion diagram for reflection coefficient compared to incident wave steepness for depth $47 \mathrm{~cm}$

Experiment results for breakwater with two porous plate: In this part, we investigate breakwater with two porous plate experiment results Table 6, Figure 9.

Table 6: reflection factor results for depth $47 \mathrm{~cm}$ with two absorbing wave

\begin{tabular}{|c|c|c|c|c|c|c|}
\hline number & T ( s ) & Hi & Hr & $\mathbf{C r}$ & $\mathbf{L}$ & $\mathbf{K}$ \\
\hline $\mathbf{1}$ & $0 / 65$ & $0 / 39$ & $0 / 19$ & $0 / 49$ & $0 / 66$ & $0 / 006$ \\
\hline $\mathbf{2}$ & $0 / 65$ & $0 / 54$ & $0 / 27$ & $0 / 50$ & $0 / 66$ & $0 / 008$ \\
\hline $\mathbf{3}$ & $0 / 78$ & $0 / 64$ & $0 / 25$ & $0 / 39$ & $0 / 95$ & $0 / 007$ \\
\hline $\mathbf{4}$ & $0 / 77$ & $1 / 17$ & $0 / 63$ & $0 / 54$ & $0 / 94$ & $0 / 013$ \\
\hline $\mathbf{5}$ & $0 / 78$ & $1 / 37$ & $0 / 54$ & $0 / 39$ & $0 / 95$ & $0 / 014$ \\
\hline $\mathbf{6}$ & $0 / 63$ & $1 / 7$ & $0 / 86$ & $0 / 51$ & $0 / 62$ & $0 / 028$ \\
\hline $\mathbf{7}$ & $0 / 78$ & $1 / 87$ & $0 / 9$ & $0 / 48$ & $0 / 95$ & $0 / 020$ \\
\hline $\mathbf{8}$ & $0 / 77$ & $1 / 86$ & $0 / 73$ & $0 / 39$ & $0 / 93$ & $0 / 020$ \\
\hline $\mathbf{9}$ & $0 / 65$ & $2 / 36$ & $0 / 95$ & $0 / 40$ & $0 / 66$ & $0 / 036$ \\
\hline $\mathbf{1 0}$ & $0 / 68$ & $2 / 5$ & $1 / 32$ & $0 / 53$ & $0 / 71$ & $0 / 035$ \\
\hline $\mathbf{1 1}$ & $0 / 85$ & $3 / 87$ & $2 / 25$ & $0 / 58$ & $1 / 13$ & $0 / 034$ \\
\hline $\mathbf{1 2}$ & $0 / 86$ & $4 / 11$ & $2 / 23$ & $0 / 54$ & $1 / 16$ & $0 / 036$ \\
\hline $\mathbf{1 3}$ & $0 / 96$ & $5 / 19$ & $2 / 76$ & $0 / 53$ & $1 / 45$ & $0 / 036$ \\
\hline $\mathbf{1 4}$ & $0 / 92$ & $4 / 85$ & $2 / 87$ & $0 / 59$ & $1 / 31$ & $0 / 037$ \\
\hline $\mathbf{1 5}$ & $0 / 93$ & $4 / 83$ & $2 / 81$ & $0 / 58$ & $1 / 35$ & $0 / 036$ \\
\hline $\mathbf{1 6}$ & $1 / 01$ & $6 / 1$ & $3 / 47$ & $0 / 57$ & $1 / 60$ & $0 / 038$ \\
\hline $\mathbf{1 7}$ & $0 / 65$ & $6 / 5$ & $3 / 06$ & $0 / 47$ & $0 / 66$ & $0 / 099$ \\
\hline $\mathbf{1 8}$ & $0 / 77$ & $9 / 68$ & $5 / 82$ & $0 / 60$ & $0 / 94$ & $0 / 104$ \\
\hline
\end{tabular}




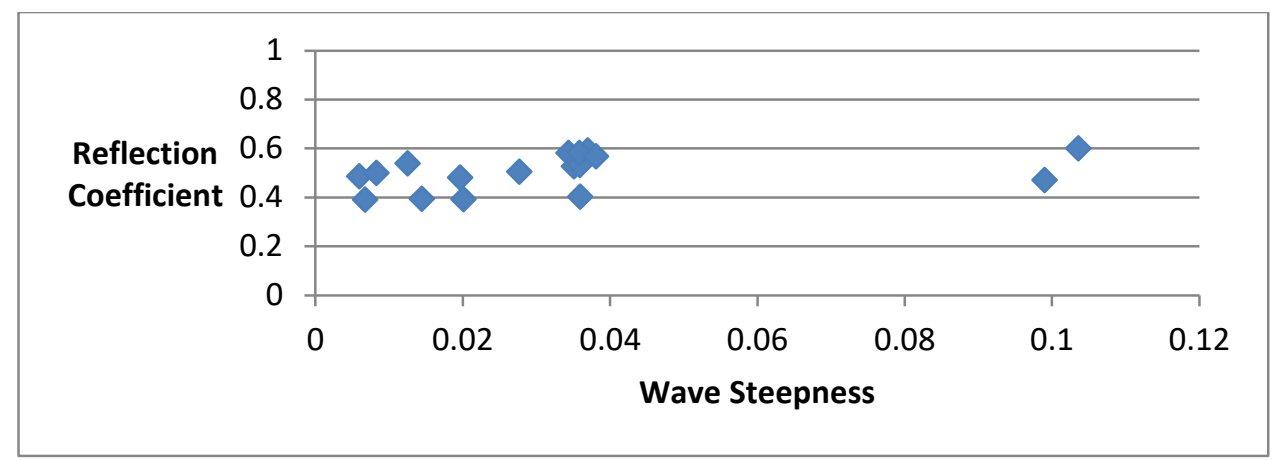

Figure 9: The dispersion diagram for reflection coefficient compared to incident wave steepness for depth $47 \mathrm{~cm}$

Experiment result comparison for breakwater with one or two porous plate: In this part, Graphs to compare the reflection coefficient when the porous plate is one (RED) or two plate (BLUE) have been determined Figure 10.

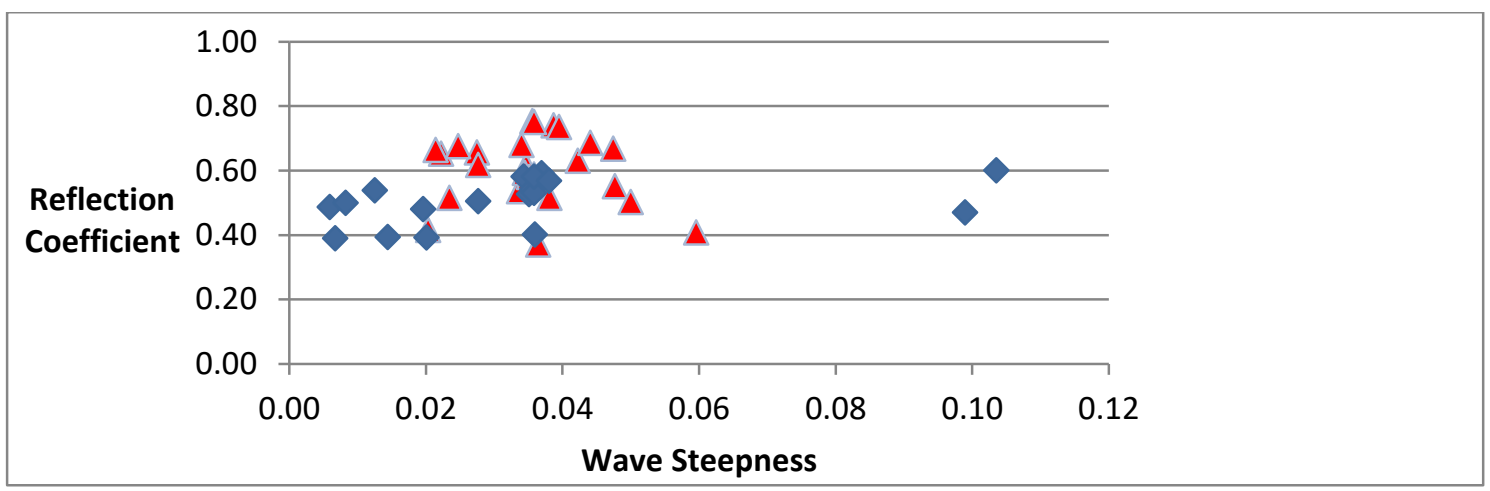

Figure 10: The dispersion diagram comparison for reflection coefficient compared to incident wave steepness for depth $47 \mathrm{~cm}$

In the below Table 7 the amount of energy dissipation for different caisson for different depths are shown.

Table 7: Amount of energy dissipation

\begin{tabular}{|c|c|c|}
\hline energy dissipation factor & $\begin{array}{c}\text { average reflection } \\
\text { coefficient in depth } \mathbf{4 7} \mathbf{c m}\end{array}$ & Caisson type \\
\hline 0.64 & 0.6 & Caisson with one porosity plate \\
\hline 0.75 & 0.5 & Caisson with two porosity plates \\
\hline
\end{tabular}

\section{CONCLUSION}

1. The average reflection coefficient for caisson with one porous plate is 60 percent while the average reflection coefficient for caisson with two porous plate is 50 percent.

2. In the laboratory, it was observed that the impact of the wave on typical caisson, standing wave is formed. So if the reflection coefficient is assumed $90 \%$ for typical caisson, the amount of 
energy loss is $19 \%$ While the amount of energy dissipation for caisson with one porous plate is $64 \%$ and the amount of energy dissipation for caisson with two porous plate is $64 \%$. It shows much difference of energy dissipation in the porous caisson and typical one.

3. In depth $47 \mathrm{~cm}$, reflection of the wave on the breakwater with one porous plate is between 37 and $75 \%$ and also reflection of the wave on the breakwater with two porous plate is between 39 and $60 \%$.

\section{REFERENCES}

1. S.Takahashi, Design of vertical breakwaters. Port and airport research institute, Japan, 1996

2. Guideline the design and implementation of coastal protection instruments. Code 629, 2017

3. Scope of work for 2D (3D) physical modelling of caisson breakwaters. South Pars Gas Field Development-SP-22-24. POGC Sulphur \& LPG export \& services Port-Site2.

\section{Corresponding author: Amin Kariman}

Master of Science, Department of Civil Engineering, College of Engineering, University of Qom, karimanmarin@gmail.com

Online date of publication: 28.01.2021 